\section{AL-AZHAR}

Assiut Dental Journal
The Official Publication of The

Faculty of Dental medicine.

Al-Azhar Assiut Uniuersity.

Egypt

AADJ, Vol. 2, No. 1, APRIL (2019) - PP. 41:49

ISSn 2682-2822

\title{
Effect of Bilateral Balanced and Monoplane Occlusion of Implant Retained Mandibular Overdenture on Biting Force and Masticatory Efficiency
}

\author{
Mostafa Abo Srie Ali ${ }^{* 1}$
}

Codex : 05/1901

Aadj@azhar.edu.eg

\section{KEYWORDS}

Key words: Bite, biting force ,overdenture, occlusion , mastication,

\begin{abstract}
Aim: To evaluate effect of bilateral balanced \& monoplane occlusion of implant retained mandibular overdenture on biting force and masticatory efficiency. Subjects and Methods: Six completely edentulous patients were selected for this study; all patients were received conventional upper and lower dentures that include bilateral balanced articulation for three months. Then each patient will receive two root form implant in the interforaminal region. The dentures processed to retrofit onto the implant. After adjustment and adaptation period occlusal biting force was recorded bilaterally at the canine and first molar area; although masticatory efficiency were evaluated by assessing chewing time and number of chewing strokes with different type of foods. Results: Significant increase in the maximum biting force and masticatory efficiency with mandibular overdentures. Conclusion: biting force and masticatory efficiency were improved with implant retained mandibular overdentures; in addition to prefer the bilateral balanced occlusion in case of biting force as it provides maximum biting force and better masticatory efficiency.
\end{abstract}

\section{INTRODUCTION}

Edentulous patients seek denture treatment to restore function and esthetics in the most comfortable function. Among the principles considered essential for complete denture success is occlusion. It has been established that complete dentures exhibit different biomechanical characteristics than natural teeth. The denture acts as one unit and any force applied to a single denture tooth will be directly transferred to the rest of the denture ${ }^{(1)}$. Mandibular implant over denture treatment is a successful treatment modality in this group of patients ${ }^{(2)}$. The over denture defined as a removable dental prosthesis that covers and rests on one or more remaining natural teeth, the roots of natural teeth, and/ or dental implants, it's also called overlay denture, overlay prosthesis, superimposed prosthesis ${ }^{(3)}$. 
An implant-supported overdenture is defined as a prosthesis that obtains its entire support from dental implants ${ }^{(3)}$; while an implant-retained overdenture is an overdenture that gains its support from a combination of intraoral tissues and dental implants ${ }^{(4)}$.

Biting force is defined as, the result of muscular force applied on opposing teeth; the force created by the dynamic action of the muscles during the physiologic act of mastication; the result of muscular activity applied to opposing teeth ${ }^{(5)}$. Bite force is one indicator of the functional state of the masticatory system that results from the action of jaw elevator muscles modified by the craniomandibular biomechanics ${ }^{(6)}$.

Determination of individual bite force level has been widely used in dentistry, mainly to understand the mechanics of mastication for evaluation of the therapeutic effects of prosthetic devices and to provide reference values for studies on the biomechanics of prosthetic devices ${ }^{(7)}$.

The biting force measurements can be made directly by using a suitable transducer that has been placed between a pair of teeth. This direct method of force assessment appears to be a convenient way of assessing the sub maximal force. An alternative method is indirect evaluation of the bite force by employing the other physiologic variables known to be functionally related to the force production. ${ }^{(8)}$

Several factors influence the direct measurements of the bite force. Thus, different investigators have found a wide range of maximum bite force values. The great variation in bite force values depends on many factors related to the anatomical and physiologic characteristics of the subjects. Apart from these factors, accuracy and precision of the bite force levels are affected by the mechanical characteristics of the bite force recording system. ${ }^{(9)}$

Masticatory efficiency is the effort required for achieving a standard degree of comminuting. ${ }^{(3)}$
Complete-denture wearers need up to seven times more chewing strokes than subjects with a complete natural dentition to reduce the food to half of the original particle size. Oral function significantly improves after mandibular implant overdenture treatment. Most studies on implant treatment and oral function showed a significant improvement of the objective masticatory performance in the mandible. ${ }^{(10)}$

The masticatory performance also significantly improved after implant treatment. ${ }^{(11)}$

The number of chewing cycles needed to have the initial size of a test food on average decreased from 47 to 25 cycles after implant treatment. ${ }^{(12)}$

Thus, after implant treatment, subjects needed only about half the number of chewing cycles as before treatment to comminute their food to a certain size. Jaw muscle activity during chewing did not significantly change after implant treatment. ${ }^{(13,14)}$

Occlusion is defined as a static relationship between the incising or masticating surface of the maxillary and mandibular teeth or teeth analogue. ${ }^{(3)}$

Occlusal scheme is defined as the form and the arrangement of the occlusal contacts in natural and artificial dentition. The choice of an occlusal scheme will determine the pattern of occlusal contacts between opposing teeth during centric relation and functional movement of the mandible. With dentures, the quantity and the intensity of these contacts determine the amount and the direction of the forces that are transmitted through the bases of the denture to the residual ridges. That is why the occlusal scheme is an important factor in the design of complete dentures. ${ }^{(15)}$

Currently, the occlusal philosophies that are proposed for implant overdentures are based on those for conventional complete dentures. ${ }^{(16)}$

The occlusal scheme described as fully bilateral balanced articulation; this occlusal scheme is designed for the bilateral, simultaneous anterior and 
posterior occlusal contact of the denture teeth in the centric and eccentric positions with a cross-arch balanced articulation. ${ }^{(17)}$

Monoplane occlusion: The monoplane concept first advocated by De Van (1954) which utilizes zero degree teeth and made the occlusal plane perfectly flat and parallel to and evenly dividing the upper and lower residual ridges. The occlusal plane was made to fall at the junction of the upper and middle third of the retromolar pad, this completely eliminates inclined planes not only in the tooth form but also in the occlusal plane, so that no lateral component can be generated with vertical chewing force. ${ }^{(18)}$

Two studies compared monoplane occlusion with conventional bilaterally balanced occlusion. ${ }^{(19)}$ Two studies of the same participant group compared conventional bilaterally balanced occlusion, lingualized bilaterally balanced occlusion, and monoplane occlusion. ${ }^{(20)}$

The crossover study by Brewer; et al. was the only study to find more patients who preferred monoplane occlusion to conventional bilaterally balanced occlusion. ${ }^{(21)}$

However the authors clearly stated that many of their participants were not aware of any difference. The other crossover study comparing conventional bilaterally balanced occlusion with monoplane occlusion demonstrated a subjective patient preference for anatomical teeth over flat teeth. ${ }^{(20)}$ This preference was attributed to the esthetic advantages and better denture stability.

\section{SUBJECTS AND METHODS}

This study was made on six completely edentulous patients; the patients were selected according to the following criteria:

- Elderly patients with completely edentulous upper and lower jaws for at least two years and no previous history of oral implant.
- Patients have problems with retention and stability of the lower denture, class 1 jaw relationship (normal maxillo-mandibular relationship).

\section{Complete denture construction:}

All the patients will receive conventional upper and lower dentures according to a standard prosthetic scheme that include bilateral balanced articulation for three months before the surgery.

\section{Recording procedures:}

A- After finishing the needed post insertion adjustments and adaptation period all the patients were recalled.

B- Occlusal biting force was recorded bilaterally at the canine and first molar regions by using the biting force device of the faculty of dentistry AL -Azhar University of assuit branch.

C- Masticatory efficiency were evaluated by assessing the chewing time and the number of chewing strokes with different type of foods (Peanuts, Carrots and Cucumbers)

D- Each patient instructed to start eating and the number and time of the chewing strokes till the first swallow is assessed then the same until complete clearance of the mouth.

\section{Surgical procedure:}

The lower denture will be duplicated into clear acrylic to be used as surgical template. Each patient will receive two root form implant in the interforaminal region, the implant will be inserted according to the parameters established by the clear acrylic template with a restrict surgical protocol under supervision of a maxillofacial surgeon, the dentures processed to retrofit onto the implant.

\section{Over denture construction:}

After finishing the needed post insertion adjustment and adaptation period and at time of denture insertion the female part of the attachments with 
their keepers will be picked to the fitting surface of the denture using the intraoral self-cure direct pickup method, after three months of denture use the patients will be ready for the recording procedures.

\section{Monoplane occlusal scheme:}

The maxillary and mandibular anterior teeth of the same over- denture were ground to no vertical overlap in lateral or protrusive mandibular movements and sufficient horizontal overlap, the posterior maxillary and mandibular teeth were removed from the over-denture base and zero degree(flat) teeth were utilized and the occlusal plane made completely flat, the teeth were attached to the over- denture base with self cured acrylic resin then finishing and polishing were done, The over- denture reinserted in the mouth with 3 weeks resting period and the patient instructed not to use any other prosthesis during that period and the same as mentioned before the biting force and the masticatory efficiency recorded .

\section{RESULTS}

The results of this study are presented as follow:

The masticatory efficiency:

Table (1) shows mean time (in seconds) and standard deviation and mean number and standard deviation of strokes with conventional denture and overdenture with Carrots.

\begin{tabular}{|c|c|c|c|c|c|c|}
\hline \multirow{2}{*}{ Item } & \multicolumn{2}{|c|}{ Conventional denture } & \multicolumn{2}{|c|}{ Over denture } & \multirow[b]{2}{*}{ T- Test } & \multirow[b]{2}{*}{ Sig. } \\
\hline & Mean & S.D & Mean & S.D & & \\
\hline Time until first swallow & 10.667 & 1.633 & 8.833 & 1.169 & $2.236^{*}$ & 0.052 \\
\hline No of strokes & 14.667 & 2.251 & 12.500 & 2.345 & 1.633 & 0.134 \\
\hline Time until total clearance of the mouth & 19.167 & 2.229 & 14.833 & 1.329 & $4.091 * *$ & 0.002 \\
\hline No of strokes(total) & 25.333 & 2.422 & 19.000 & 2.608 & $4.359 * *$ & 0.001 \\
\hline
\end{tabular}

$*$ = significant difference. $* *=$ High significant difference.. S.D $=$ Standard deviation.

Table (2) shows mean time (in seconds) and standard deviation and mean number and standard deviation of strokes with conventional denture and over denture with Cucumber

\begin{tabular}{|c|c|c|c|c|c|c|}
\hline \multirow{2}{*}{ Item } & \multicolumn{2}{|c|}{ Conventional denture } & \multicolumn{2}{|c|}{ Over denture } & \multirow{2}{*}{ T- Test } & \multirow{2}{*}{ Sig. } \\
\hline & Mean & S.D & Mean & S.D & & \\
\hline Time until first swallow & 13.500 & 0.548 & 7.333 & 0.516 & $20.066 * *$ & 0.000 \\
\hline No of strokes & 14.500 & 1.871 & 7.667 & 1.211 & $7.511 * *$ & 0.000 \\
\hline Time until total clearance of the mouth & 24.833 & 0.408 & 14.500 & 0.837 & $27.189 * *$ & 0.000 \\
\hline No of strokes(total) & 25.333 & 1.506 & 15.167 & 2.137 & $9.527 * *$ & 0.000 \\
\hline
\end{tabular}

$*=$ significant difference $. * *=$ High significant difference. S.D $=$ Standard deviation. 
Table (3) shows mean time (in seconds) and standard deviation and mean number and standard deviation of strokes with conventional denture and over denture with Peanuts.

\begin{tabular}{|c|c|c|c|c|c|c|}
\hline \multirow{2}{*}{ Item } & \multicolumn{2}{|c|}{ Conventional denture } & \multicolumn{2}{|c|}{ Over denture } & \multirow[b]{2}{*}{ T- Test } & \multirow[b]{2}{*}{ Sig. } \\
\hline & Mean & S.D & Mean & S.D & & \\
\hline Time until first swallow & 18.667 & 1.862 & 9.000 & 1.549 & $9.776 * *$ & 0.000 \\
\hline No of strokes & 18.667 & 2.338 & 13.333 & 2.658 & $3.690 * *$ & 0.004 \\
\hline Time until total clearance of the mouth & 29.000 & 3.033 & 19.167 & 2.639 & $5.991 * *$ & 0.000 \\
\hline No of strokes(total) & 34.000 & 4.472 & 25.167 & 4.535 & $3.397 * *$ & 0.007 \\
\hline
\end{tabular}

$*=$ significant difference. $\quad * *=$ High significant difference. $\quad$ S.D $D=$ Standard deviation.

Table (4) Shows mean Time (in seconds) and standard deviation and the Duncan's test until first swallow of Carrots, Cucumber and Peanuts with bilateral balanced\& monoplane occlusion) of the overdenture.

\begin{tabular}{|c|c|c|c|c|}
\hline Food type & Occlusion & Mean & S.D & DT \\
\hline \multirow{3}{*}{ Carrot } & Balanced & 8.833 & 1.169 & $\mathrm{C}$ \\
\cline { 2 - 5 } & Monoplane & 10.167 & 1.643 & $\mathrm{~B}$ \\
\hline \multirow{2}{*}{ Cucumber } & Balanced & 9.00 & 0.516 & $\mathrm{C}$ \\
\cline { 2 - 5 } & Monoplane & 10.833 & 0.408 & $\mathrm{~B}$ \\
\hline \multirow{3}{*}{ Peanuts } & Balanced & 9.500 & 1.549 & $\mathrm{C}$ \\
\cline { 2 - 5 } & Monoplane & 12.333 & 3.204 & $\mathrm{~A}$ \\
\hline
\end{tabular}

Table (5) Shows mean number of strokes and standard deviation and the Duncan's test until first swallow of Carrots, Cucumber and Peanuts with bilateral balanced\& monoplane occlusion of the overdenture.

\begin{tabular}{|c|c|c|c|c|}
\hline Food type & Occlusion & Mean & S.D & DT \\
\hline \multirow{2}{*}{ Carrot } & Balanced & 12.5 & 2.345 & C \\
\cline { 2 - 5 } & Monoplane & 13.83 & 2.229 & B \\
\hline \multirow{2}{*}{ Cucumber } & Balanced & 11.67 & 1.211 & C \\
\cline { 2 - 5 } & Monoplane & 13.33 & 0.983 & B \\
\hline \multirow{3}{*}{ Peanuts } & Balanced & 11.167 & 2.658 & $\mathrm{C}$ \\
\cline { 2 - 5 } & Monoplane & 16.67 & 2.338 & $\mathrm{~A}$ \\
\hline
\end{tabular}

*:a significant difference.

**: High significant difference.

$S . D=$ Standard deviation .

DT =Duncan's Multiple Range Test.Means with the same letter within each column and food type are not significantly different at $(p<0,05)$.
Table (6) Shows mean time(in seconds) and standard deviation and the Duncan's test until clearance of the mouth of Carrots, Cucumber and Peanuts with (bilateral balanced\& monoplane occlusion) of the overdenture

\begin{tabular}{|c|c|c|c|c|}
\hline Food type & Occlusion & Mean & S.D & DT \\
\hline \multirow{2}{*}{ Carrot } & Balanced & 16.00 & 1.329 & C \\
\cline { 2 - 5 } & Monoplane & 17.83 & 2.317 & A \\
\hline \multirow{2}{*}{ Cucumber } & Balanced & 14.83 & 0.837 & D \\
\cline { 2 - 5 } & Monoplane & 17.17 & 0.408 & B \\
\hline \multirow{3}{*}{ Peanuts } & Balanced & 16.83 & 2.639 & B \\
\cline { 2 - 5 } & Monoplane & 19.17 & 3.061 & A \\
\hline
\end{tabular}

Table(7) Shows the mean number of strokes and standard deviation and the Duncan's test until clearance of the mouth of Carrots, Cucumber and Peanuts with (bilateral balanced\&monoplane occlusion) of the overdenture.

\begin{tabular}{|c|c|c|c|c|}
\hline Food type & Occlusion & Mean & S.D & DT \\
\hline \multirow{2}{*}{ Carrot } & Balanced & 19.00 & 2.608 & C \\
\cline { 2 - 5 } & Monoplane & 23.67 & 2.160 & B \\
\hline \multirow{2}{*}{ Cucumber } & Balanced & 18.5 & 2.137 & C \\
\cline { 2 - 5 } & Monoplane & 22.67 & 0.548 & B \\
\hline \multirow{2}{*}{ Peanuts } & Balanced & 19.17 & 4.535 & C \\
\cline { 2 - 5 } & Monoplane & 25.17 & 1.862 & A \\
\hline
\end{tabular}




\section{The Biting force:}

Table (8) Shows the mean value of the biting force (in kilograms) and standard deviation at the canine and first molar area for conventional denture and the overdenture.

\begin{tabular}{|c|c|c|c|c|c|c|}
\hline \multirow{2}{*}{$\begin{array}{c}\text { Biting } \\
\text { force }\end{array}$} & \multicolumn{2}{|c|}{$\begin{array}{c}\text { Conventional } \\
\text { denture }\end{array}$} & \multicolumn{2}{|c|}{ Over denture } & \multirow{2}{*}{ T- Test } & Sig. \\
\cline { 2 - 5 } & Mean & S.D & Mean & S.D & & \\
\hline $\begin{array}{c}\text { Canine } \\
\text { area }\end{array}$ & 10.00 & 1.23 & 14.27 & 1.41 & $11.30^{* *}$ & 0.000 \\
\hline $\begin{array}{c}\text { First } \\
\text { molar } \\
\text { area }\end{array}$ & 10.08 & 1.23 & 16.84 & 1.71 & $11.38^{* *}$ & 0.000 \\
\hline
\end{tabular}

*:a significant difference.

**: High significant difference.

$S . D=$ Standard deviation

Table (9) shows the mean value and standard deviation of the biting force (in kilograms) and the Duncan's test at the canine area for Balanced occlusion, monoplane occlusion of the overdenture.

\begin{tabular}{|c|c|c|c|c|}
\hline Biting force & Occlusion & Mean & S.D & DT \\
\hline \multirow{2}{*}{ Canine area } & $\begin{array}{c}\text { Balanced } \\
\text { occlusion }\end{array}$ & 14.87 & 1.48 & $\mathrm{~A}$ \\
\cline { 2 - 5 } & $\begin{array}{c}\text { Monoplane } \\
\text { occlusion }\end{array}$ & 13.28 & 1.16 & $\mathrm{C}$ \\
\hline \multirow{2}{*}{ First molar area } & $\begin{array}{c}\text { Balanced } \\
\text { occlusion }\end{array}$ & 16.84 & 1.71 & $\mathrm{~A}$ \\
\cline { 2 - 5 } & $\begin{array}{c}\text { Monoplane } \\
\text { occlusion }\end{array}$ & 15.80 & 1.69 & $\mathrm{C}$ \\
\hline
\end{tabular}

*:a significant difference.

**: High significant difference.

$S . D=$ Standard deviation. $D T=$ Duncan's Multiple Range Test. Means with the same letter within each column are not significantly different at $(p<0,05)$. (value of $A>B>C$ )

\section{DISCUSSION}

\section{The Biting force:}

The results of this study showed a significant increase in the maximum biting force after the mandibular dentures were attached to implants, these results are in agreement with findings reported by Van Kampen, et al.,(2002) ${ }^{(22)}$. Who stated that improvement of oral function after implant treatment, the maximum bite force of subjects with a mandibular denture supported by implants was $60-200 \%$ higher than that of subjects with a conventional denture. And in agreement with findings reported in previous studies by Stellingsma; et al.(2005). ${ }^{(11)}$ which revealed that directly after implant treatment, significant increase in maximum bite force and chewing performance were reported.

The results of this study showed that there were an increase in the biting force at the first molar area than at the canine area for both conventional denture and overdenture, these results are in agreement with Tortopidis; et al.(1998) ${ }^{(23)}$ who stated that the more posteriorly the transducer is placed in dental arch, the greater the bite force, in addition greater bite force can be tolerated better in posterior teeth, because of larger area and periodontal ligament around posterior teeth roots.

The results of this study showed that a significant increase in the bite force with the bilaterally balanced occlusion than the monoplane occlusion both at the canine area and the first molar area these results in agreement with withBakke M, (2006). ${ }^{(24)}$ Who suggested that the number of occlusal contacts is a stronger determinant of muscle action and bite force than the number of teeth.

\section{The Masticatory efficiency:}

The results of the present study shows a significant increase in the masticatory efficiency (decreased number of strokes and time until first swallow also until clearance of the mouth) when the overdentures were used, these results are in agreement with VanKampen; et al.,(2004)(12), K.Stellingsma; et al.(2005) ${ }^{(11)}$ they stated that the masticatory performance significantly improved after implant treatment. 
The results of the present study shows significant reduction in masticatory efficiency of monoplane occlusion when compared with bilateral balanced occlusion, these results are in agreement with the finding of other studies)., Ohguri; et al., (1999). ${ }^{(25)}$ They pointed out that the reduction in masticatory efficiency of the monoplane occlusion could be attributed to the decrease in the cutting efficiency of non-cusped teeth.

This also agree with the two crossover study Sutton\&McCord, $(2007)^{(26)}$,. Worthington; et al., (2007) $^{(27)}$ that assessed the difference between ligualized bilateral balanced, conventional bilateral balanced and monoplane occlusion, found that the use of anatomical teeth in ligualized bilateral balanced, conventional bilateral balanced was subjectively superior to the use of flat teeth in monoplane occlusion.

\section{CONCLUSIONS}

Within limitation of this study, the conclusions are:

1. Improved biting force and masticatory efficiency with implant retained mandibular overdenture.

2. The bilateral balanced occlusion preferred in case of biting force as it provides maximum biting force and better masticatory efficiency (less time \& number of strokes) than monoplane occlusion.

\section{REFERENCES}

1. Fenton AH, Chang T-L, Zarb GA, Hobkirk JA, Eckert $\mathrm{SE}$, Jaccob RF( eds).The selection and arrangement of occlusal surfaces of prosthetic teeth in edentulous patients. Prosthodontic treatment for complete dentures and implant-supported prosthesis.St Louis: Elsevier Mosby, 2012:204-229.

2. Fueki, K., Kimoto, K., Ogawa, T. \& Garrett, N.R. Effect of implant-supported or retained dentures on masticatory performance:asystematic review. Journal Of Prosthetic Dentistry.2007;98:470-477.

3. Academy of prosthodontics. The Academy of Prosthodontics. J Prosthodont. Dent.2005; 97 : 94-110.
4. Simon H, Yanase RT. Terminology for implant prostheses. Int J Oral Maxillofac Implants 2003;18:539-543.

5. Donovan R, Fetner A, Koutouzis T, Lundgren T. Crestal bone changes around implants with reduced abutment diameter placed non-submerged and at subcrestal positions: a 1-year radiographic evaluation. J Periodontol. Mar 2010;81(3): 428-34.

6. Palmer RM, Smith BJ, Howe Lc, Palmer PJ. implant in clinical dentistry Gillingham, Kent, united kingdom, Martin Dunitz;2002.

7. Fernandes Cp,Glantz PJ, Svensson SA, Bergmark A. Anovel sensor for bite force determination. Dent Mater. 2003;19:118-126.

8. Ferrario VF, Sforza C, ZanottiG,Tartagilia GM. Maximal bite force in healthy young adults as predicted by surface electromyography. J Dent. 2004;32:451-457.

9. Van Der Bilt A, Tekamp FA, Van Der GlasHW,Abbink $\mathrm{JH}$. Bite force and electromyography during maximum unilateral and bilateral clenching.Eur $\mathrm{J}$ Oral Sci. 2008;116:217-222.

10. Bakke M, Holm B, Gotfredsen K. Masticatory function and patient satisfaction with implant-supported mandibular overdentures: aprospective 5-year study. Int J Prosthodont. 2002; 15:575-581.

11. Stellingsma K, Slagter A.P, Stegenga B, Raghoe-bar, G.M and Meijer H.J.A. Masticatory function in patients with extremely resorbed mandible restored by mandibular implant retained overdentures: comparison of three types of treatment protocols. Journal of Oral Rehabil .2005; 32:403-410.

12. Van Kampen, F.M.C, Van Der Bilt A. Cune M.S, FontijnTekamp, F.A. and Bosman F . Masticatory function with implant-supported overdentures.J.Dent. Res. 2004; 83:708-711.

13. Van Der Bilt A, Van Kampen, F.M.C and Cune M.S. Masticatory function with implant-supported overdentures fitted with different attachment types. European Journal of Oral Sciences.2006;114:191-196.

14. Berretin- Felix G, Nary Filho H, Padovani, C.R, Trindade Junior A.S and Machado W.M. Elecromyographic evaluation of mastication and swallowing in eldery individuals with mandibular fixed implant-supported prosthesis. Journal of Applied Oral Science . 2008 ;16:116-121.

15. Tarazi E, Ticotsky-Zadok N. Occlusal schemes of complete dentures a review of the literature. Refuathapehvehashinayim . 2007; 24:56-64,85-86. 
16. Kim Y, Oh TJ, Misch CE, Wang HI.Occlusal considerations in implant therapy: clinical guidelines with biomechanical rationale. Clin Oral Implants Res 2005;16:26-35.

17. The glossary of prosthodonticterms. J Prosthet Dent 2005; 94.

18. De Van, M.M. The concept of neurocentric occlusion as related to denture stability. J. Am.Dent.Assoc. 1954 ; 48:165-169.

19. Shetty NS.Comparative observations of the use of cups and zero degree posterior teeth. J Prosthet Dent 1984; 51:459-460.

20. Sutton AF, Worthington HV, McCord JF, RCT. Comparing posteriorocclusal forms for complete dentures. J Dent Res 2007;86:651-655.

21. Brewer AA, Reibel PR, Nassif NJ.Comparisonof zero degreeteeth and anatomic teeth on complet dentures. J Prosthet Dent 1967;17:28-35.

22. Van Kampen FM, Van Der Belt A., Cune MS., Bosman F. The influence of various attachment types in mandibular implant-retained overdentures on maximum bite force and EMG. J. Dent. Res. 2002;81:170-73.

23. Tortopidis D, Lyons MF, Baxendle RH, Gilmour WH.The variability of bite force measurements between sessions, in different positions within the dental arch. J Oral Rehabil. 1998; 25:681-686.

24. 24-Bakke M. Bite Force and occlusion.Semin Orthod. 2006;12:120-126.

25. Ohguri T., Kawano F., Ichikawa T., and Mastumoton D. Influence of occlusalsheme on the pressure distribution under completdenture, Int. J. Prosthodont.1999; 12(4):353-8.

26. Sutton AF, McCord JF.Arandomized clinical trial comparing anatomic lingualized, and zero-degree posterior occlusal forms for complete dentures .J Prosthet Dent 2007;97:292-298.

27. Worthington H.V., Sutton AF, McCord JF, RCT. Comparing posteriorocclusal forms for complete dentures. J Dent Res 2007;86:651-655. 


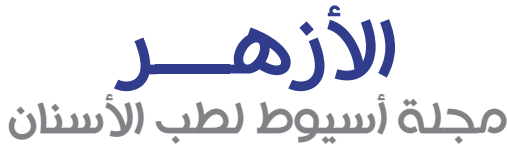

النشر الرسمي لكلية طب الأسنان

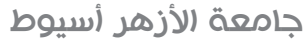

AADJ, Vol. 2, No. 1, April (2019) - PP. 49

الملخص العربي

المقدمة:

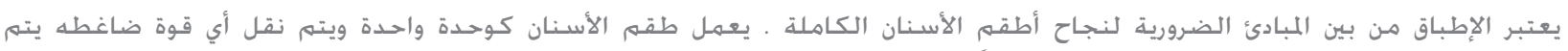

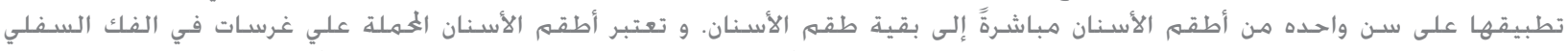

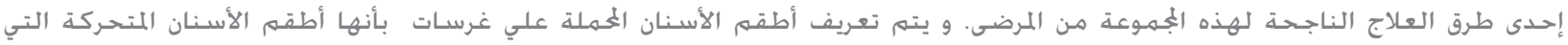

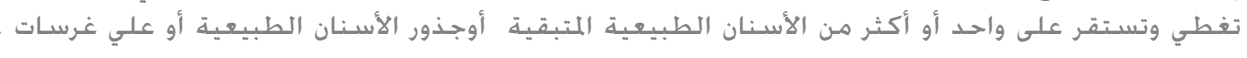

\section{الموضوعات والأساليب:}

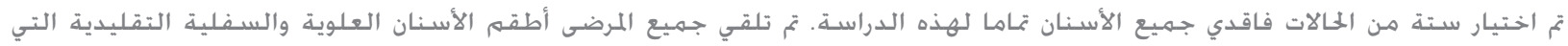

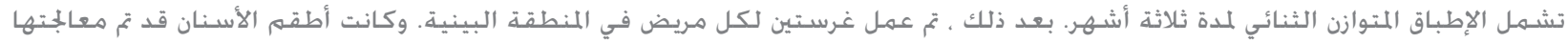

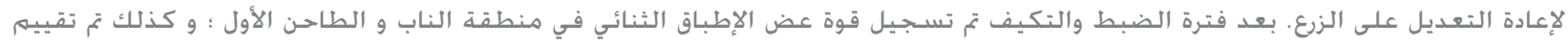

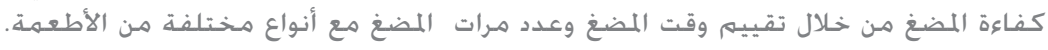

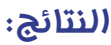

زيادة كبيرة في الحد الأقصى لقوة العض وكفاءة المضغ مع أطقى الأسنان الخمعلة علي غرسـات الفك السفلي.

الاستنتاجات: - اج

تم ثَسين قوة العض وكفاءة المضغ مع أطقم الأسـنان العُملة علي غرسات الفك السفلي

بالإضافة إلى تفضيل أطقىم الأسـنان العمملة علي غرسـات التي تشـمل الإطباق المتوازن الثنائي في حالة قوة العض لأنه يوفر أقصى قوة عض تص وكفاءة مضغية أفضل. 